\title{
POETRY
}

\section{The explosion at a Glock Plant in Georgia}

\section{Dedicated to Rep. Gabrielle Giffords of Tucson, Arizona}

Left one man dead, though he arrived at Grady Hospital, "in critical condition," another man in "satisfactory," according to the spokesman, and a woman, unhurt though dazed, like the witness to a sniper's spree awake for everything; it is most likely she who will develop "post-traumatic stress" so much later than one might ever guess -

But after the explosion's hour on Yahoo! all news of it vanished into the ether. Only the Augusta Chronicle wrote it up, while the Michigan Shooter never asked: When an explosion takes out a gun plant, how many lives are saved? Instead, the magazine laments the airlines' lack of armed pilots and crows that a bill to ban assault rifles would slowly be left to die - as it did.

What was the name of the man who died that day, in the Glock plant?

I scour the web for more news of this explosion, and finding none, news of explosions at other gun plants, all the thousands of them, the glimmering origins of somebody's death, functioning and whole.

In other news: in California, the dough-muscled Austro-American Action Star turned governor campaigns against automatic weapons as though he had never seen a single one of his films, or maybe, having seen them to the point of nausea, devoted his political life to repentance.

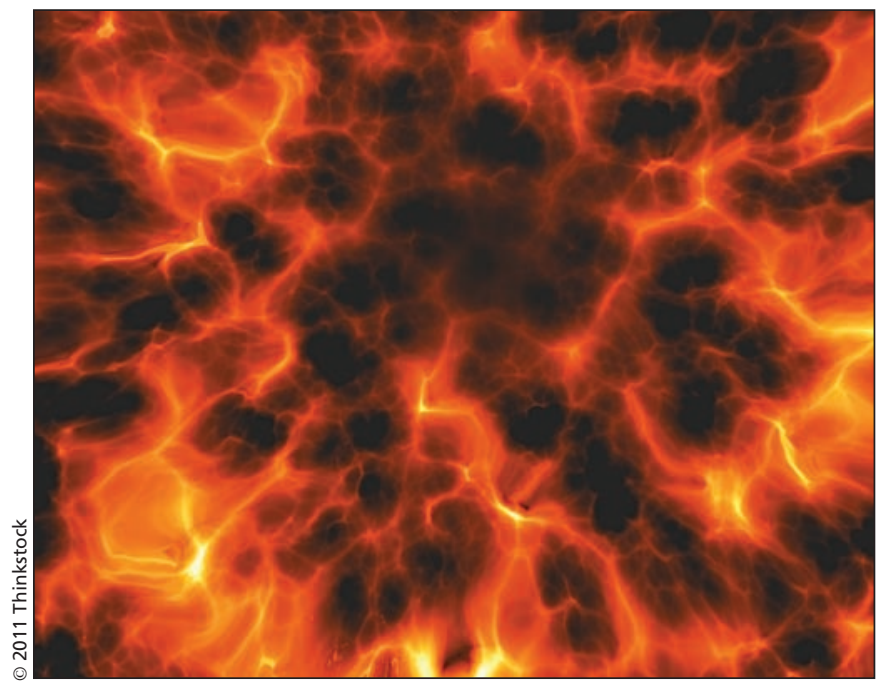

The Glock plant in Georgia is gone, or maybe it's been rebuilt and enlarged, joining its fellow plants for whose music some must suffer a lacerated bowel or undergo surgery to lift a shattered bit of skull or spend weeks under fluorescent lights as a trauma counselor attempts to restore her sanity, her voice.

\section{Ron Charach MD}

Psychiatrist in private practice Toronto, Ont.

This poem is included in Ron Charach's new book, Forgetting the Holocaust (Frontenac House, 2011).

CMAJ 2011. DOI:10.1503/cmaj.111247 